Cancer Drug Discovery and Development $\bullet$ Series Editor: Beverly A. Teicher $\bullet$ SpringerNature

Preprint Version • February 2020

\title{
Molecular Targeted Radiosensitizers: Opportunities and Challenges
}

\author{
Henning Willers, $\mathrm{MD}^{1}$ and Iris Eke, $\mathrm{MD}^{\mathrm{PhD}^{2}}$ \\ ${ }^{1}$ Massachusetts General Hospital, Harvard Medical School, Boston, Massachusetts, USA \\ ${ }^{2}$ Stanford University School of Medicine, Stanford, California, USA
}

\begin{abstract}
The practice of radiation oncology is currently primarily based on precise technical delivery of highly conformal, image-guided radiation treatments. The precision medicine revolution has provided radiation oncologists with tremendous opportunities to enhance the anti-tumor effects of radiation therapy, potentially with less normal tissue toxicity than traditional chemotherapeutic radiosensitizers. However, a tremendous body of pre-clinical research and clinical investigations on radiosensitizers has not yet translated into any meaningful number of FDA-approved combinations of radiation with targeted radiosensitizers +/- chemotherapy. There exist distinct challenges to clinical translation of radiation/drug combinations that the field is only beginning to appreciate. These considerations have served as motivation for this Volume, which provides a comprehensive review by experts in the field of key pre-clinical research components required to identify effective and safe (chemo-)radiosensitizing drugs. Readers will be provided with a detailed and timely insight into the framework of targeted radiosensitizer research coupled with recent developments in immuno-oncology. Ultimately, this Volume will support the identification of appropriately validated and biomarker-directed targeted drug/radiation combinations that will have a higher likelihood than in the past to be incorporated into standard management of human cancers. These developments, coupled with the increasing technical power of radiation therapy to safely increase local control for many solid tumors, are expected to improve survival outcomes and cure rates for our patients.
\end{abstract}

Keywords: Biomarkers, Cancer stem cells, Clonogenic survival assays, Hallmarks of cancer, Molecular targeted radiosensitizers, Molecular targets, Preclinical models, Radiosensitization, Tumor heterogeneity

Correspondence: Henning Willers, MD, Department of Radiation Oncology, Massachusetts General Hospital, 55 Fruit Street, Boston, MA 02114; Tel. 617-726-5184, email: hwillers@ @mgh.harvard.edu 


\section{Preface}

It has been almost an entire century since Dr. Hermann Holthusen of Hamburg, Germany, correctly surmised that the relationship between the probability of tumor control and the total dose of radiation delivered can be described by a sigmoid data fit on linear scales (Strahlentherapie 57, 254-69 1936). Similarly, the probability of normal tissue complications with increasing dose follows a sigmoid dose-response relationship. Achieving near 100\% tumor control while having a very low likelihood of severe complications remains the quintessential goal of curative radiation therapy. Because the maximum dose of radiation that can be safely delivered is limited by the radiation tolerance of the normal tissues and organs surrounding the tumor, there has been a longstanding interest in combining radiation with drugs that can increase radiation-mediated tumor cell kill but without substantially increasing normal tissue toxicity. However, treatment combinations of radiation with biological sensitizers or enhancers have had very limited clinical success to date. The challenges to successful clinical translation of these agents have served as motivation for this Volume. Here, we provide a comprehensive review by experts in the field of key pre-clinical research components required to identify effective and safe radiosensitizing drugs. We sincerely hope that ultimately this text will help harness the tremendous opportunities that these drugs offer to increase the likelihood of uncomplicated cures in our cancer patients.

We are indebted to all authors for their hard work contributing outstanding reviews, despite their busy schedules! It has been a true pleasure to compile the chapters and assemble what we believe is a uniquely comprehensive and timely overview of this exciting and fast-moving field that the readers will enjoy.

We could not have tackled the task of editing this book without the teachings of many mentors and educators in our field, including Michael Baumann, Hans-Peter Beck Bornholdt, Norm Coleman, Nils Cordes, Kathy Held, Simon Powell, and Herman Suit. A special thanks also goes to Jeff Settleman and the Dana-Farber/Harvard Cancer Center SPORE in Lung Cancer for inspiring the application of precision oncology concepts to the study of radiation/drug combinations more than 10 years ago.

We are also intensely grateful for the love and support of our families. Without their tolerance for after-hours and weekend work this project would not have come to fruition.

Lastly, we are deeply motivated and inspired by our patients - whose lives we saved and whose lives we lost. Biological advances in radiation therapy that will extend lives or achieve new cures cannot arrive soon enough.

Boston, Massachusetts

Henning Willers, MD

Stanford, California

Iris Eke, $\mathrm{MD}, \mathrm{PhD}$

February 2020 


\section{Contents}

1. Introduction to Molecular Targeted Radiosensitizers: Opportunities and Challenges Henning Willers and Iris Eke

2. Translating Targeted Radiosensitizers into the Clinic Deborah E. Citrin and Kevin A. Camphausen

3. Cartography of the Radiogenome of Human Cancers Priyanka Gopal, Jessica A. Castrillon, and Mohamed E. Abazeed

4. Mechanisms and Markers of Clinical Radioresistance Michael Binkley, Max Diehn, Iris Eke, and Henning Willers

5. Preclinical Strategies for Testing of Targeted Radiosensitizers Steven H. Lin, Rui Ye, and Yifan Wang

6. 3D Radiation Biology for Studying Radiosensitizers Anne Vehlow, Sara Sofia Deville, and Nils Cordes

7. Preclinical In Vivo Evaluation of Novel Radiosensitizers by Local Tumor Control Experiments Karolin Schneider, Nadja Ebert, Ina Kurth, and Michael Baumann

8. Genetically Engineered Mouse Models for Studying Radiation Biology and Radiosensitizers Warren Floyd, Hsuan-Cheng Kuo, Jonathon E. Himes, Rutulkumar Patel, and David G. Kirsch

9. Targeting the DNA Damage Response for Radiosensitization Matthew T. McMillan, Theodore S. Lawrence, and Meredith A. Morgan

10. Targeting Tumor Metabolism to Overcome Radioresistance Daniel Wahl, Michael Petronek, Rashmi Ramachandran, John Floberg, Bryan G. Allen, and Julie K. Schwarz

\section{Targeting Tumor Hypoxia} Michael Skwarski, Elizabeth Bowler, Joseph D. Wilson, Geoff S. Higgins, and Ester M. Hammond

12. Normalizing the Tumor Microenvironment for Radiosensitization John D. Martin and Rakesh K. Jain

13. Radiosensitizers in the Era of Immuno-Oncology Jonathan E. Leeman and Jonathan D. Schoenfeld 


\section{Chapter 1}

\section{Introduction to Molecular Targeted Radiosensitizers: Opportunities and Challenges}

Henning Willers and Iris Eke

H Willers

Dept. of Radiation Oncology, Massachusetts General Hospital, Harvard Medical School, Boston, MA hwillers@mgh.harvard.edu

I Eke

Dept. of Radiation Oncology, Stanford University School of Medicine, Stanford, CA iris.eke@stanford.edu 


\begin{abstract}
The practice of radiation oncology is currently primarily based on precise technical delivery of highly conformal, image-guided radiation treatments. The precision medicine revolution has provided radiation oncologists with tremendous opportunities to enhance the anti-tumor effects of radiation therapy, potentially with less normal tissue toxicity than traditional chemotherapeutic radiosensitizers. However, a tremendous body of pre-clinical research and clinical investigations on radiosensitizers has not yet translated into any meaningful number of FDA-approved combinations of radiation with targeted radiosensitizers $+/$ - chemotherapy. There exist distinct challenges to clinical translation of radiation/drug combinations that the field is only beginning to appreciate. These considerations have served as motivation for this Volume, which provides a comprehensive review by experts in the field of key pre-clinical research components required to identify effective and safe (chemo-)radiosensitizing drugs. Readers will be provided with a detailed and timely insight into the framework of targeted radiosensitizer research coupled with recent developments in immuno-oncology. Ultimately, this Volume will support the identification of appropriately validated and biomarker-directed targeted drug/radiation combinations that will have a higher likelihood than in the past to be incorporated into standard management of human cancers. These developments, coupled with the increasing technical power of radiation therapy to safely increase local control for many solid tumors, are expected to improve survival outcomes and cure rates for our patients.
\end{abstract}




\section{Opportunities for Targeted Radiosensitizers}

Radiation therapy is an important treatment modality that is given to over $50 \%$ of cancer patients at some time during the course of their disease (Bristow et al. 2018). The goal of curative radiation therapy is to sterilize all cancer stem cells (CSC) or CSC-like cells that could give rise to a local tumor recurrence while limiting injury to normal tissues around the tumor and to the patient (Willers et al. 2019). Curative radiation is often combined with surgery or/and chemotherapy depending on cancer type, tumor stage, and other factors. In clinical settings where cure is not possible, radiation can provide palliation or extend progression-free survival in conjunction with systemic therapies. However, in many patients, the dose of radiation that can be safely administered is insufficient to achieve high rates of local tumor control and cure. In others, normal tissue injury may be a concern even at moderate doses. Ideally, in these settings, radiation would be combined with drugs that can enhance its tumoricidal effects (local or even abscopal) but without or only little added toxicity (Bristow et al. 2018; Baumann et al. 2016; Kirsch et al. 2018; Lin et al. 2013b).

\subsection{Molecular Targeted Drugs}

Over the past two decades, cancer therapy has been revolutionized by personalized (or precision) medicine, with prominent examples being the use of small molecule inhibitors against chronic myeloid leukemia driven by the BCR-ABL fusion protein or non-small cell lung cancer (NSCLC) cancers with oncogenic mutations in the epidermal growth factor receptor (EGFR) (Cohen et al. 2002; Lynch et al. 2004). Molecular targeted therapy can be defined as blocking a target that controls biological processes critical to the initiation and maintenance of cancer. Ideally, the target should be measurable in the clinic and measurement of the target should correlate with clinical benefit following administration of the targeted therapy (Sledge 2005). The arrival of targeted therapies has enabled oncologists to try to turn incurable cancers into chronic disease, or to the very last achieve significant prolongations of progressionfree survival (Chong and Janne 2013).

Importantly, many of the cellular pathways that promote tumor growth and survival may also play a role in response to treatment with ionizing radiation, suggesting that their pharmacological inhibition could cause tumor radiosensitization (Bristow et al. 2018). For example, while EGFR signaling may drive tumor growth in the small subset of NSCLC patients whose tumors harbor activating mutations in its tyrosine kinase domain, wild-type EGFR is expressed in the majority of lung and other cancers where it potentially can modulate responses to radiation (Baumann et al. 2007). However, targeting EGFR for radiosensitization has only been successful in an unselected population of patients with head and neck squamous cell carcinomas treated without chemotherapy, and has failed in other clinical settings (Bonner et al. 2006; Bradley et al. 2019; Gillison et al. 2019; Ang et al. 2014).

Important differences in the utility of targeted drugs in mono-therapy versus their use as radiosensitizer likely exist and are summarized in Figure 1.1. Traditionally, radiosensitizers have been regarded as effective in unselected patients, similar to the concept of combining radiation with chemotherapy. However, it appears increasingly possible that this "one-size-fits-all" approach is not viable in the clinic and that targeted agents only radiosensitize subsets of tumors, which would require predictive biomarkers to identify those patients who are most likely to benefit. Alternatively, biomarkers may be employed to identify radioresistant or radiosensitive strata of patients. The use of targeted agents with chemoradiation, which could be associated with increased toxicity, may only be justified in patients with radioresistant disease. 


\subsection{Predictive Biomarkers}

Molecular targeted drugs can produce dramatic clinical responses in subsets of patients with disseminated cancer. The discovery of these agents has been concurrent with the characterization of the molecular genetic changes in an individual's tumor that can play a critical role in determining the clinical response to a particular drug. Human cancers vary enormously in their somatic genetic alterations, and it is becoming widely accepted that these genetic differences, even in tumors with the same basic histological features, are the important determinants of response to these targeted drugs. The genomic characterization of human cancers that has been fueled by the successes of targeted drugs now also provides a basis for a more rational, biologically informed use of radiation therapy, with or without the addition of targeted radiosensitizers (Hall et al. 2017; Eke et al. 2016b; Kamran and Mouw 2018).

Analogous to the concept of precision medicine, "precision radiation medicine" may thus leverage genomic information derived from human cancers or preclinical tumor models to identify subsets that are sensitive to specific radiation/drug combinations, or radiation alone. Genomic biomarkers of radiosensitization may include oncogenic driver mutations, as increasingly found in for example lung cancers, or passenger mutations that do not affect tumor cell growth/survival in the absence of radiation exposure but that become important determinants of survival once cells suffer radiation damage. This remains a vastly understudied area, particularly in comparison with recent advances in matching drugalone sensitivities to oncogenic driver mutations. Furthermore, as we are acquiring a deeper understanding of the hallmarks of cancer and how they may differ across individual tumors and patients, we will be in a better position to identify molecular targets for tumor radiosensitization (Figure 1.2) (Willers et al. 2019). Importantly, many of the hallmarks of cancer are intimately linked to effects of radiation, examples being the impact of DNA repair alterations on radiosensitvity and the role of local immune escape on radiation response (Boss et al. 2014).

\subsection{Targeted Radiosensitizers and Immunotherapy}

As we have firmly entered the era of immuno-oncology, what does this mean for the preclinical and clinical development of targeted radiosensitizers? In the future, immunotherapy rather than targeted radiosensitizers may be used to enhance tumor control and cures in many patients with solid tumors. However, it can be assumed that immunotherapy will not be of benefit in all cancer patients so that targeted radiosensitizers will retain their importance in at least subsets of patients. In addition, increasing evidence suggests that targeted radiosensitizers, particular DNA repair inhibitors, can modulate the immune response (Zhang et al. 2019; Konstantinopoulos et al. 2019; Vendetti et al. 2018). This opens up an exciting area for investigation into novel radiation/drug regimens. Lastly, immune checkpoint inhibitors may themselves have radiosensitizing properties (Azad et al. 2017; Deng et al. 2014; Crittenden et al. 2018).

Taken together, combining molecular targeted and immuno-modulating agents with radiation continues to show great promise both to radiosensitize tumours as well as to maximize protection of normal tissues. For many promising targets agents and immune checkpoint inhibitors, one of their greatest effects in oncology could ultimately rest in their combination with established treatment modalities such as radiation with/without chemotherapy to further cure and survival rates (Bristow et al. 2018). 


\section{Challenges for Targeted Radiosensitizers}

Preclinical and clinical drug development with radiation therapy has been considered of critical importance to cancer research (Lawrence et al. 2013; Colevas et al. 2003; Harrington et al. 2011; Katz et al. 2009; Bristow et al. 2018). However, a large body of preclinical radiation/drug studies has not translated into an adequate number of successful radiation trials (Lawrence et al. 2013; Morris and Harari 2014). In fact, cetuximab remains to this date the only molecular targeted agent approved by the U.S. Food and Drug Administration - for use with radiation therapy in head and neck cancers (Bonner et al. 2006). A number of reasons likely exist, many of which have been discussed (Higgins et al. 2015; Lawrence et al. 2013; Lin et al. 2013b; Morris and Harari 2014; Coleman et al. 2016; Stone et al. 2016). Here, we wish to highlight what could be some of the most pressing challenges to the identification of successful radiation/drug combinations for the clinic.

\subsection{Reproducibility of Preclinical Radiation Data}

Preclinical evaluation of radiation effects is challenging due to the need to measure loss of replicative tumor cell potential, integrate concurrent chemotherapy which is the standard-of-care in many cancer types, and model the impact of the tumor microenvironment (Morgan et al. 2014). Furthermore, radiosensitizing drug effects in clonogenic survival assays (CSA) are often small with dose enhancement factors much below 2. This stands in contrast to the effects of targeted drugs on in vitro measures of tumor response, i.e., a reduction in cell number/viability, which is often pronounced (Barretina et al. 2012; Garnett et al. 2012).

These challenges are compounded by shortcomings in the design and reporting of radiation/drug experiments according to a recent review of 125 publications by Stone and colleagues (Stone et al. 2016). The authors described a large number of instances in which experimental studies contained inadequate or unclear information (222 problems in 104 in vitro studies and 109 problems in 51 in vivo experiments). These issues could hamper efforts to replicate or compare the data and weaken the evidence for any subsequent clinical trials. Areas needing improvement include:

1. Authentication of cell lines and testing for pathogens such as mycoplasma

2. Sufficient information on drug source, storage, vehicle, preparation, concentrations, et cetera.

3. Description of radiation source, irradiation set-up, dosimetry, and other factors, including traceability of output verification of X-ray tube to National Standards

4. Information on in vitro and in vivo drug administration schedules, including exact timing and relationship to irradiation, and the underlying rationale

5. Proper conduct of CSA

6. Information on number of independent biological repeats performed

7. Inclusion of full data set in supplement if representative data are shown

8. Appropriate statistical analysis of results in consultation with a statistician

9. Blinded counting of colonies and outcome assessments wherever possible

10. For mouse experiments, detailed descriptions that include tumor size at start of treatment, whether treatment was started when tumors reached a given size or at a given time after implantation. Tumors should be sufficiently large at the start of treatment to have biological properties of established tumors and to facilitate accurate measurement. Information on tumor transplantation procedure, site, method and frequency of measurement, et cetera. 
The authors stressed that preclinical radiation/drug studies should meet standards of design, execution, and interpretation, and report necessary information to ensure high quality and reproducibility of studies. These improvements may provide a more robust basis for prioritizing drugs for clinical radiation therapy trials and for the design of such trials.

\subsection{Modeling of Clinically Relevant Intertumoral Heterogeneity}

Established cancer cell lines remain critically important for mechanistic studies of radiation/drug interactions, target validation, and in vivo confirmation as xenografts. Traditionally, radiation/drug combinations have been studied in limited numbers of cell lines (Kleiman et al. 2013; Lin et al. 2014; Carmichael et al. 1987; Wang et al. 2001; Lally et al. 2007). However, any radiosensitizing effects in one or a few cell lines may not be representative of efficacy in an unselected larger number of genetically heterogeneous tumors, which may only be revealed when the agent under study has entered clinical trials. Historically, the choice of targeted radiosensitizers has conformed to a "one-size-fits-all" philosophy, but it is becoming increasingly possible that radiosensitizing effects are tumor genotype-dependent, which would require predictive biomarkers for appropriate patient selection (Lin et al. 2013a; Das et al. 2010; Liu et al. 2015; Willers and Hong 2015; Wang et al. 2018). Therefore, an appropriate number of human cancer-derived cell lines, for a given tumor type, may need to mirror the number of cell lines used in previous drug-alone screens, i.e., dozens per cancer type, given our emerging knowledge of the considerable genetic heterogeneity of tumors even within the same cancer type and histology (Network 2012; Imielinski et al. 2012; Neve et al. 2006; Sos et al. 2009; Garnett et al. 2012; Barretina et al. 2012; Iorio et al. 2016). A larger number of cell lines would be needed to identify potential associations of radiosensitization with genomic alterations that have a low but still clinically relevant frequency of, for instance, $10-15 \%$ in the population.

The CSA has been considered the gold standard for assessing the cell-inactivating effects of radiation in vitro (Puck and Marcus 1956; Katz et al. 2008; Kahn et al. 2012). However, CSAs are not ideal for the kind of high-throughput screens that are needed to match diverse genomic tumor profiles with radiation/drug sensitivities owing to the frequently poor colony forming ability of human cancer cell lines and the time it takes to conduct these assays. Short-term cell viability/survival assays, on the other hand, are historically not considered to provide appropriate surrogate endpoints of clonogenic survival (Lin et al. 2014; Brown and Wouters 1999; Brown and Wilson 2003). However, plate formats have been successfully tested and provide an opportunity for examining larger numbers of genomically characterized cancer cell lines and targeted drugs than have been historically pursued (Yard et al. 2016; Liu et al. 2015; Wang et al. 2014; Lin et al. 2014; Eke et al. 2016a). More work is required to validate these different approaches.

\subsection{Integration of Experimental Approaches}

Coleman and colleagues recently outlined a bench-to-bedside workflow to identify the most promising radiation/drug combinations for clinical testing (Coleman et al. 2016). This workflow involves an initial unbiased screening of cancer cell lines with radiation/drug combinations, followed by refinement and validation of "hits", after which tumor efficacy and treatment toxicity are assessed in appropriate animal models. An adapted preclinical workflow is shown in Figure 1.3, and discussed below. Preclinical development of radiation/drug combos in such a manner is expected to be resource-intensive and timeconsuming and requires integration of synergistic preclinical tumor models and capabilities of several institutions (for example, NCI FOA PAR-16-111). 


\section{In Vitro Screening}

As discussed above, initial testing of radiation/drug combinations may employ an appropriate number of authenticated cancer cell lines whose genomic and phenotypic characteristics are representative of the tumor type being studied. Treatment of one or a few cell lines with radiosensitizing agents likely produces biased results that will not translate into a more diverse tumor population. Drugs need to be given at multiple concentrations that are achievable in patients and have no or little toxicity by itself. Consideration should be given to pursuing more physiologic in vitro culturing conditions that better resemble in vivo tumor growth (such as use of 3D growth formats, extracellular matrix, physiologic oxygen concentrations, patient-derived cell line models and co-cultures). Initial investigations of immunotherapies or targeted drugs that interact with the tumor microenvironment have to be conducted in appropriate in vivo models such as genetically engineered mouse models (GEMM) (Castle et al. 2017), or perhaps in ex vivo systems (Jenkins et al. 2018).

\section{In Vitro Validation}

Screening results should be confirmed with CSA whenever possible. Additional assays may consider CSC-like cells that are relevant for radioresistance, for example through the use of tumor spheres. In vitro validation may also include assessing the impact of concurrently administered chemotherapeutics on radiosensitizing drug effects although laboratory modeling of clinically relevant dosing and timing of chemotherapies is not trivial. The inclusion of patient-derived tumor models is recommended if the initial screen was done on established cancer cell lines. For other tasks, see Figure 1.3. In general, this step narrows down the number of compounds that will undergo more expensive and time-consuming animal testing.

\section{In Vivo Testing}

Initial tumor models may be xenografts derived from genomically characterized cell lines used in the in vitro investigation or appropriate PDX models. Assessment of efficacy in murine models should consider treatments that are clinically relevant, including fractionated radiation and standard-of-care chemoradiation regimens. This approach provides initial assessments of drug efficacy, mechanistic insight as well as pharmacokinetic/pharmacodynamic measures. However, results from tumor growth delay assays may not always be consistent with the results of local control (TCD50) assays (Gurtner et al. 2011; Krause et al. 2006). TCD50 assays are performed much less commonly than growth delay assays because of the larger number of animals required and higher cost (Coleman et al. 2016). Nevertheless, before clinical trials with curative endpoints are initiated, TCD50 assays, which better reflect CSC inactivation, should be considered to reduce the chance of a negative trial. Additional animal models such as GEMMs harboring a natural tumor microenvironment and an intact immune system are also important components within the preclinical pipeline before bringing radiation/drug combos into the clinic (see Figure 1.3).

The above considerations have served as motivation for this Volume, which provides a comprehensive review by experts in the field of key preclinical research components required to identify effective and safe (chemo-)radiosensitizing drugs. Readers are provided with a detailed and timely insight into the framework of targeted radiosensitizer research coupled with recent developments in immuno-oncology. Ultimately, this Volume will support the identification of appropriately validated, and potentially biomarker-directed, targeted drug/radiation combinations that will have a higher likelihood than in the past to be incorporated into standard management of human cancers. These developments, coupled with the increasing technical power of radiation therapy to safely increase local control for many solid tumors, are expected to improve survival outcomes and cure rates for our patients. 


\section{In this Volume}

Citrin and Camphausen (Ch. 2) provide a comprehensive review on the unique challenges that clinical translation and testing of targeted radiosensitizers present. These include how to best sequence agents and radiation, establishing biomarkers of efficacy, and integration into the current standard of care which includes cytotoxic chemotherapy in many settings. The authors conclude that an expanding knowledge of the underlying mechanisms of resistance and recurrence after radiation therapy coupled with the growing capacity to molecularly profile tumors provide great hope for future progress in this field. Abazeed and colleagues (Ch. 3) introduce the readers to pre-clinical studies of radiation responses and targeted sensitizers. They focus on the review our emerging knowledge of tumor and normal tissue genomics and their impact on the outcomes after radiation therapy (i.e., the "radiogenome"). They emphasize that given this knowledge population-based estimates of treatment effects increasingly cannot be justified. Critically, genomic tumor and patient features have considerable potential to serve as predictive biomarkers that can guide the clinical development of targeted radiosensitizers. Because targeted radiosensitizers or chemoradiosensitizers are expected to have particular utility in the treatment of radioresistant cancers, we summarize clinically relevant mechanisms of radiation resistance (Ch. 4). Of particular interest are tumor mutations in KEAPl as well as KRAS, which define an emerging area of need for intensification of radiation-based treatment regimens.

Starting a series of Chapters on pre-clinical models for the study of targeted radiosensitizers, Lin and colleagues (Ch. 5) provide a comprehensive overview of preclinical strategies for testing of targeted radiosensitizers with a focus on clonogenic and non-clonogenic screening assays. They also review published guidelines and recommendations for the conduct of these studies. Three-dimensional (3D) cell cultures are well suited to model the extracellular matrix of tumors and provide more physiological treatment responses than traditional 2D cell cultures, as reviewed by Cordes and colleagues (Ch. 6). In particular, radioresistance and the effects of radiosensitizing agents are effectively captured by 3D tumor models, which comprise an important level of investigation before moving drug testing into animals. Baumann and colleagues (Ch. 7) discuss the conduct of radiation and radiation/drug studies in different mouse models. While every model has advantages and disadvantages, the use of genomically defined heterotopic xenograft tumor models facilitates testing of clinically relevant radiation dose fractionation schedules and assessments of local tumor control. Kirsch and colleagues (Ch. 8) review the advantages of genetically engineered mouse models for the study of targeted radiosensitizers as well as radiation biology in general. These include preservation of the natural tumor microenvironment, ability to assess clinically relevant normal tissue injury, precise temporal and spatial control of genetic alterations that may affect radiation/drug responses, and lastly, the presence of an intact immune system.

Moving on to clinically promising therapeutic targets, Morgan and colleagues (Ch. 9) provide an in-depth review of clinically relevant small molecule inhibitors directed against kinases in the cellular DNA damage response (DDR). Of special interest is the recently recognized link of DDR targets to immunomodulation which creates opportunities for novel radiation/drug regimens. The promise of targeting altered cellular metabolism, a hallmark of cancer, is comprehensively addressed by Schwarz, Allen, and colleagues (Ch. 10). Preclinical and clinical evidence support the combined use of a number of metabolically targeted agents with radiation therapy, including those that affect nucleotide metabolism, glutaminolysis, oxidative stress, or iron metabolism. Hammond and colleagues (Ch. 11) provide an overview of tumor hypoxia, long known to limit the effectiveness of radiation therapy. Novel therapeutic approaches are emerging that include targeting oxidative metabolism in tumors. The authors emphasize the need for clinical development of hypoxia biomarkers without which patients most likely to benefit cannot be selected for hypoxia-targeted treatment strategies. Jain and Martin (Ch. 12) describe pioneering 
work on the effects that the altered tumor microenvironment has on cancer therapy outcomes including radiation. Novel approaches to inhibit tumor angiogenesis and desmoplasia can normalize the tumor microenvironment towards alleviating hypoxia and reversing radioresistance. The authors stress the need for appropriate pre-clinical models and imaging tools to identify optimal combinations of radiation with anti-angiogenic treatments, mechanotherapeutics, chemotherapy, and immune checkpoint inhibitors in the context of TME normalization. Lastly, Leeman and Schoenfeld (Ch. 13) provide an overview of the rapidly expanding field of radiation combined with immune checkpoint inhibitors, both with regard to enhancing local tumor control as well as eliciting abscopal effects. Because molecular targeted agents are being increasingly recognized as having immuno-modulatory effects, additional opportunities, as well as challenges, exist for multi-modality approaches that employ radiation and systemic combinations of chemotherapy, targeted agents, and/or checkpoint inhibitors. 


\section{References}

Ang KK, Zhang Q, Rosenthal DI, Nguyen-Tan PF, Sherman EJ, Weber RS, Galvin JM, Bonner JA, Harris J, El-Naggar AK, Gillison ML, Jordan RC, Konski AA, Thorstad WL, Trotti A, Beitler JJ, Garden AS, Spanos WJ, Yom SS, Axelrod RS (2014) Randomized phase III trial of concurrent accelerated radiation plus cisplatin with or without cetuximab for stage III to IV head and neck carcinoma: RTOG 0522. J Clin Oncol 32 (27):29402950. doi:10.1200/JCO.2013.53.5633

Azad A, Yin Lim S, D'Costa Z, Jones K, Diana A, Sansom OJ, Kruger P, Liu S, McKenna WG, Dushek O, Muschel RJ, Fokas E (2017) PD-L1 blockade enhances response of pancreatic ductal adenocarcinoma to radiotherapy. EMBO Mol Med 9 (2):167-180. doi:10.15252/emmm.201606674

Barretina J, Caponigro G, Stransky N, Venkatesan K, Margolin AA, Kim S, Wilson CJ, Lehar J, Kryukov GV, Sonkin D, Reddy A, Liu M, Murray L, Berger MF, Monahan JE, Morais P, Meltzer J, Korejwa A, Jane-Valbuena J, Mapa FA, Thibault J, Bric-Furlong E, Raman P, Shipway A, Engels IH, Cheng J, Yu GK, Yu J, Aspesi P, Jr., de Silva M, Jagtap K, Jones MD, Wang L, Hatton C, Palescandolo E, Gupta S, Mahan S, Sougnez C, Onofrio RC, Liefeld T, MacConaill L, Winckler W, Reich M, Li N, Mesirov JP, Gabriel SB, Getz G, Ardlie K, Chan V, Myer VE, Weber BL, Porter J, Warmuth M, Finan P, Harris JL, Meyerson M, Golub TR, Morrissey MP, Sellers WR, Schlegel R, Garraway LA (2012) The Cancer Cell Line Encyclopedia enables predictive modelling of anticancer drug sensitivity. Nature 483 (7391):603-607

Baumann M, Krause M, Dikomey E, Dittmann K, Dorr W, Kasten-Pisula U, Rodemann HP (2007) EGFR-targeted anti-cancer drugs in radiotherapy: preclinical evaluation of mechanisms. Radiother Oncol 83 (3):238-248

Baumann M, Krause M, Overgaard J, Debus J, Bentzen SM, Daartz J, Richter C, Zips D, Bortfeld T (2016) Radiation oncology in the era of precision medicine. Nat Rev Cancer 16 (4):234-249. doi:10.1038/nrc.2016.18

Bonner JA, Harari PM, Giralt J, Azarnia N, Shin DM, Cohen RB, Jones CU, Sur R, Raben D, Jassem J, Ove R, Kies MS, Baselga J, Youssoufian H, Amellal N, Rowinsky EK, Ang KK (2006) Radiotherapy plus cetuximab for squamous-cell carcinoma of the head and neck. N Engl J Med 354 (6):567-578. doi:10.1056/NEJMoa053422

Boss MK, Bristow R, Dewhirst MW (2014) Linking the history of radiation biology to the hallmarks of cancer. Radiat Res 181 (6):561-577. doi:10.1667/RR13675.1

Bradley JD, Hu C, Komaki RR, Masters GA, Blumenschein GR, Schild SE, Bogart JA, Forster KM, Magliocco AM, Kavadi VS, Narayan S, lyengar P, Robinson CG, Wynn RB, Koprowski CD, Olson MR, Meng J, Paulus R, Curran WJ, Jr., Choy H (2019) Long-Term Results of NRG Oncology RTOG 0617: Standard- Versus HighDose Chemoradiotherapy With or Without Cetuximab for Unresectable Stage III Non-Small-Cell Lung Cancer. J Clin Oncol:JCO1901162. doi:10.1200/JCO.19.01162

Bristow RG, Alexander B, Baumann M, Bratman SV, Brown JM, Camphausen K, Choyke P, Citrin D, Contessa JN, Dicker A, Kirsch DG, Krause M, Le QT, Milosevic M, Morris ZS, Sarkaria JN, Sondel PM, Tran PT, Wilson GD, Willers H, Wong RKS, Harari PM (2018) Combining precision radiotherapy with molecular targeting and immunomodulatory agents: a guideline by the American Society for Radiation Oncology. Lancet Oncol 19 (5):e240-e251. doi:10.1016/S1470-2045(18)30096-2

Brown JM, Wilson G (2003) Apoptosis genes and resistance to cancer therapy: what does the experimental and clinical data tell us? Cancer Biol Ther 2 (5):477-490

Brown JM, Wouters BG (1999) Apoptosis, p53, and tumor cell sensitivity to anticancer agents. Cancer Res 59 (7):1391-1399

Carmichael J, DeGraff WG, Gazdar AF, Minna JD, Mitchell JB (1987) Evaluation of a tetrazolium-based semiautomated colorimetric assay: assessment of radiosensitivity. Cancer Res 47 (4):943-946

Castle KD, Chen M, Wisdom AJ, Kirsch DG (2017) Genetically engineered mouse models for studying radiation biology. TransI Cancer Res 6 (Suppl 5):S900-S913. doi:10.21037/tcr.2017.06.19

Chong CR, Janne PA (2013) The quest to overcome resistance to EGFR-targeted therapies in cancer. Nat Med 19 (11):1389-1400. doi:10.1038/nm.3388 
Cohen MH, Williams G, Johnson JR, Duan J, Gobburu J, Rahman A, Benson K, Leighton J, Kim SK, Wood R, Rothmann M, Chen G, U KM, Staten AM, Pazdur R (2002) Approval summary for imatinib mesylate capsules in the treatment of chronic myelogenous leukemia. Clin Cancer Res 8 (5):935-942

Coleman CN, Higgins GS, Brown JM, Baumann M, Kirsch DG, Willers H, Prasanna PG, Dewhirst MW, Bernhard EJ, Ahmed MM (2016) Improving the Predictive Value of Preclinical Studies in Support of Radiotherapy Clinical Trials. Clin Cancer Res 22 (13):3138-3147. doi:10.1158/1078-0432.CCR-16-0069

Colevas AD, Brown JM, Hahn S, Mitchell J, Camphausen K, Coleman CN (2003) Development of investigational radiation modifiers. J Natl Cancer Inst 95 (9):646-651

Crittenden MR, Zebertavage L, Kramer G, Bambina S, Friedman D, Troesch V, Blair T, Baird JR, Alice A, Gough MJ (2018) Tumor cure by radiation therapy and checkpoint inhibitors depends on pre-existing immunity. Sci Rep 8 (1):7012. doi:10.1038/s41598-018-25482-w

Das AK, Bell MH, Nirodi CS, Story MD, Minna JD (2010) Radiogenomics predicting tumor responses to radiotherapy in lung cancer. Semin Radiat Oncol 20 (3):149-155

Deng L, Liang H, Burnette B, Beckett M, Darga T, Weichselbaum RR, Fu YX (2014) Irradiation and anti-PD-L1 treatment synergistically promote antitumor immunity in mice. J Clin Invest 124 (2):687-695. doi:10.1172/JCl67313

Eke I, Hehlgans S, Sandfort V, Cordes N (2016a) 3D matrix-based cell cultures: Automated analysis of tumor cell survival and proliferation. Int J Oncol 48 (1):313-321. doi:10.3892/ijo.2015.3230

Eke I, Makinde AY, Aryankalayil MJ, Ahmed MM, Coleman CN (2016b) Comprehensive molecular tumor profiling in radiation oncology: How it could be used for precision medicine. Cancer Lett 382 (1):118-126. doi:10.1016/j.canlet.2016.01.041

Garnett MJ, Edelman EJ, Heidorn SJ, Greenman CD, Dastur A, Lau KW, Greninger P, Thompson IR, Luo X, Soares J, Liu Q, lorio F, Surdez D, Chen L, Milano RJ, Bignell GR, Tam AT, Davies H, Stevenson JA, Barthorpe S, Lutz SR, Kogera F, Lawrence K, McLaren-Douglas A, Mitropoulos X, Mironenko T, Thi H, Richardson L, Zhou W, Jewitt F, Zhang T, O'Brien P, Boisvert JL, Price S, Hur W, Yang W, Deng X, Butler A, Choi HG, Chang JW, Baselga J, Stamenkovic I, Engelman JA, Sharma SV, Delattre O, Saez-Rodriguez J, Gray NS, Settleman J, Futreal PA, Haber DA, Stratton MR, Ramaswamy S, McDermott U, Benes CH (2012) Systematic identification of genomic markers of drug sensitivity in cancer cells. Nature 483 (7391):570-575

Gillison ML, Trotti AM, Harris J, Eisbruch A, Harari PM, Adelstein DJ, Sturgis EM, Burtness B, Ridge JA, Ringash J, Galvin J, Yao M, Koyfman SA, Blakaj DM, Razaq MA, Colevas AD, Beitler JJ, Jones CU, Dunlap NE, Seaward SA, Spencer S, Galloway TJ, Phan J, Dignam JJ, Le QT (2019) Radiotherapy plus cetuximab or cisplatin in human papillomavirus-positive oropharyngeal cancer (NRG Oncology RTOG 1016): a randomised, multicentre, non-inferiority trial. Lancet 393 (10166):40-50. doi:10.1016/S0140-6736(18)32779-X

Gurtner K, Deuse Y, Butof R, Schaal K, Eicheler W, Oertel R, Grenman R, Thames H, Yaromina A, Baumann M, Krause M (2011) Diverse effects of combined radiotherapy and EGFR inhibition with antibodies or TK inhibitors on local tumour control and correlation with EGFR gene expression. Radiother Oncol 99 (3):323-330. doi:10.1016/j.radonc.2011.05.035

Hall WA, Bergom C, Thompson RF, Baschnagel AM, Vijayakumar S, Willers H, Li A, Schultz CJ, Wilson GD, West CML, Capala J, Coleman CN, Torres-Roca JF, Weidhaas J, Feng FY (2017) Precision Oncology and Genomically Guided Radiation Therapy, A Report From the ASTRO/AAPM/NCI Precision Medicine Conference. Int J Radiat Oncol Biol Phys in press

Harrington KJ, Billingham L, Brunner TB, Burnet NG, Chan CS, Hoskin P, Mackay RI, Maughan TS, Macdougall J, McKenna WG, Nutting CM, Oliver A, Plummer R, Stratford IJ, Illidge T (2011) Guidelines for preclinical and early phase clinical assessment of novel radiosensitisers. Br J Cancer 105 (5):628-639

Higgins GS, O'Cathail SM, Muschel RJ, McKenna WG (2015) Drug radiotherapy combinations: review of previous failures and reasons for future optimism. Cancer Treat Rev 41 (2):105-113.

doi:10.1016/j.ctrv.2014.12.012

Imielinski M, Berger AH, Hammerman PS, Hernandez B, Pugh TJ, Hodis E, Cho J, Suh J, Capelletti M, Sivachenko A, Sougnez C, Auclair D, Lawrence MS, Stojanov P, Cibulskis K, Choi K, de Waal L, Sharifnia T, Brooks A, Greulich H, Banerji S, Zander T, Seidel D, Leenders F, Ansen S, Ludwig C, Engel-Riedel W, Stoelben E, 
Wolf J, Goparju C, Thompson K, Winckler W, Kwiatkowski D, Johnson BE, Janne PA, Miller VA, Pao W, Travis WD, Pass HI, Gabriel SB, Lander ES, Thomas RK, Garraway LA, Getz G, Meyerson M (2012)

Mapping the hallmarks of lung adenocarcinoma with massively parallel sequencing. Cell 150 (6):11071120

lorio F, Knijnenburg TA, Vis DJ, Bignell GR, Menden MP, Schubert M, Aben N, Goncalves E, Barthorpe S, Lightfoot $H$, Cokelaer T, Greninger P, van Dyk E, Chang H, de Silva H, Heyn H, Deng X, Egan RK, Liu Q, Mironenko T, Mitropoulos X, Richardson L, Wang J, Zhang T, Moran S, Sayols S, Soleimani M, Tamborero D, LopezBigas N, Ross-Macdonald P, Esteller M, Gray NS, Haber DA, Stratton MR, Benes CH, Wessels LF, SaezRodriguez J, McDermott U, Garnett MJ (2016) A Landscape of Pharmacogenomic Interactions in Cancer. Cell 166 (3):740-754. doi:10.1016/j.cell.2016.06.017

Jenkins RW, Aref AR, Lizotte PH, Ivanova E, Stinson S, Zhou CW, Bowden M, Deng J, Liu H, Miao D, He MX, Walker W, Zhang G, Tian T, Cheng C, Wei Z, Palakurthi S, Bittinger M, Vitzthum H, Kim JW, Merlino A, Quinn M, Venkataramani C, Kaplan JA, Portell A, Gokhale PC, Phillips B, Smart A, Rotem A, Jones RE, Keogh L, Anguiano M, Stapleton L, Jia Z, Barzily-Rokni M, Canadas I, Thai TC, Hammond MR, Vlahos R, Wang ES, Zhang H, Li S, Hanna GJ, Huang W, Hoang MP, Piris A, Eliane JP, Stemmer-Rachamimov AO, Cameron L, Su MJ, Shah P, Izar B, Thakuria M, LeBoeuf NR, Rabinowits G, Gunda V, Parangi S, Cleary JM, Miller BC, Kitajima S, Thummalapalli R, Miao B, Barbie TU, Sivathanu V, Wong J, Richards WG, Bueno R, Yoon CH, Miret J, Herlyn M, Garraway LA, Van Allen EM, Freeman GJ, Kirschmeier PT, Lorch JH, Ott PA, Hodi FS, Flaherty KT, Kamm RD, Boland GM, Wong KK, Dornan D, Paweletz CP, Barbie DA (2018) Ex Vivo Profiling of PD-1 Blockade Using Organotypic Tumor Spheroids. Cancer Discov 8 (2):196-215. doi:10.1158/2159-8290.CD-17-0833

Kahn J, Tofilon PJ, Camphausen K (2012) Preclinical models in radiation oncology. Radiat Oncol 7:223

Kamran SC, Mouw KW (2018) Applying Precision Oncology Principles in Radiation Oncology. JCO Precis Oncol DOI: 10.1200/PO.18.00034:1-23

Katz D, Ito E, Lau KS, Mocanu JD, Bastianutto C, Schimmer AD, Liu FF (2008) Increased efficiency for performing colony formation assays in 96-well plates: novel applications to combination therapies and highthroughput screening. Biotechniques 44 (2):ix-xiv

Katz D, Ito E, Liu FF (2009) On the path to seeking novel radiosensitizers. Int J Radiat Oncol Biol Phys 73 (4):988996

Kirsch DG, Diehn M, Kesarwala AH, Maity A, Morgan MA, Schwarz JK, Bristow R, Demaria S, Eke I, Griffin RJ, Haas-Kogan D, Higgins GS, Kimmelman AC, Kimple RJ, Lombaert IM, Ma L, Marples B, Pajonk F, Park CC, Schaue D, Tran PT, Willers H, Wouters BG, Bernhard EJ (2018) The Future of Radiobiology. J Natl Cancer Inst 110 (4):329-340. doi:10.1093/jnci/djx231

Kleiman LB, Krebs AM, Kim SY, Hong TS, Haigis KM (2013) Comparative analysis of radiosensitizers for K-RAS mutant rectal cancers. PLoS One 8 (12):e82982

Konstantinopoulos PA, Waggoner S, Vidal GA, Mita M, Moroney JW, Holloway R, Van Le L, Sachdev JC, ChapmanDavis E, Colon-Otero G, Penson RT, Matulonis UA, Kim YB, Moore KN, Swisher EM, Farkkila A, D'Andrea A, Stringer-Reasor E, Wang J, Buerstatte N, Arora S, Graham JR, Bobilev D, Dezube BJ, Munster P (2019) Single-Arm Phases 1 and 2 Trial of Niraparib in Combination With Pembrolizumab in Patients With Recurrent Platinum-Resistant Ovarian Carcinoma. JAMA Oncol. doi:10.1001/jamaoncol.2019.1048

Krause M, Zips D, Thames HD, Kummermehr J, Baumann M (2006) Preclinical evaluation of molecular-targeted anticancer agents for radiotherapy. Radiother Oncol 80 (2):112-122

Lally BE, Geiger GA, Kridel S, Arcury-Quandt AE, Robbins ME, Kock ND, Wheeler K, Peddi P, Georgakilas A, Kao GD, Koumenis C (2007) Identification and biological evaluation of a novel and potent small molecule radiation sensitizer via an unbiased screen of a chemical library. Cancer Res 67 (18):8791-8799

Lawrence YR, Vikram B, Dignam JJ, Chakravarti A, Machtay M, Freidlin B, Takebe N, Curran WJ, Jr., Bentzen SM, Okunieff P, Coleman CN, Dicker AP (2013) NCI-RTOG translational program strategic guidelines for the early-stage development of radiosensitizers. J Natl Cancer Inst 105 (1):11-24

Lin SH, George TJ, Ben-Josef E, Bradley J, Choe KS, Edelman MJ, Guha C, Krishnan S, Lawrence TS, Le QT, Lu B, Mehta M, Peereboom D, Sarkaria J, Seong J, Wang D, Welliver MX, Coleman CN, Vikram B, Yoo S, Chung 
$\mathrm{CH}$ (2013a) Opportunities and challenges in the era of molecularly targeted agents and radiation therapy. J Natl Cancer Inst 105 (10):686-693

Lin SH, George TJ, Ben-Josef E, Bradley J, Choe KS, Edelman MJ, Guha C, Krishnan S, Lawrence TS, Le QT, Lu B, Mehta M, Peereboom D, Sarkaria J, Seong J, Wang D, Welliver MX, Coleman CN, Vikram B, Yoo S, Chung $\mathrm{CH}$, Participants on Workshop for P, Clinical Development of R, National Cancer I (2013b) Opportunities and challenges in the era of molecularly targeted agents and radiation therapy. J Natl Cancer Inst 105 (10):686-693. doi:10.1093/jnci/djt055

Lin SH, Zhang J, Giri U, Stephan C, Sobieski M, Zhong L, Mason KA, Molkentine J, Thames HD, Yoo SS, Heymach JV (2014) A High Content Clonogenic Survival Drug Screen Identifies MEK Inhibitors as Potent Radiation Sensitizers for KRAS Mutant Non-Small-Cell Lung Cancer. J Thorac Oncol 9 (7):965-973

Liu Q, Wang M, Kern AM, Khaled S, Han J, Yeap BY, Hong TS, Settleman J, Benes CH, Held KD, Efstathiou JA, Willers H (2015) Adapting a Drug Screening Platform to Discover Associations of Molecular Targeted Radiosensitizers with Genomic Biomarkers. Mol Cancer Res 13:713-720

Lynch TJ, Bell DW, Sordella R, Gurubhagavatula S, Okimoto RA, Brannigan BW, Harris PL, Haserlat SM, Supko JG, Haluska FG, Louis DN, Christiani DC, Settleman J, Haber DA (2004) Activating mutations in the epidermal growth factor receptor underlying responsiveness of non-small-cell lung cancer to gefitinib. N Engl J Med 350 (21):2129-2139

Morgan MA, Parsels LA, Maybaum J, Lawrence TS (2014) Improving the efficacy of chemoradiation with targeted agents. Cancer Discov 4 (3):280-291. doi:10.1158/2159-8290.CD-13-0337

Morris ZS, Harari PM (2014) Interaction of radiation therapy with molecular targeted agents. J Clin Oncol 32 (26):2886-2893. doi:10.1200/JCO.2014.55.1366

Network CGAR (2012) Comprehensive genomic characterization of squamous cell lung cancers. Nature 489 (7417):519-525

Neve RM, Chin K, Fridlyand J, Yeh J, Baehner FL, Fevr T, Clark L, Bayani N, Coppe JP, Tong F, Speed T, Spellman PT, DeVries S, Lapuk A, Wang NJ, Kuo WL, Stilwell JL, Pinkel D, Albertson DG, Waldman FM, McCormick F, Dickson RB, Johnson MD, Lippman M, Ethier S, Gazdar A, Gray JW (2006) A collection of breast cancer cell lines for the study of functionally distinct cancer subtypes. Cancer Cell 10 (6):515-527

Puck TT, Marcus PI (1956) Action of x-rays on mammalian cells. J Exp Med 103 (5):653-666

Sledge GW, Jr. (2005) What is targeted therapy? J Clin Oncol 23 (8):1614-1615. doi:10.1200/JCO.2005.01.016

Sos ML, Michel K, Zander T, Weiss J, Frommolt P, Peifer M, Li D, Ullrich R, Koker M, Fischer F, Shimamura T, Rauh D, Mermel C, Fischer S, Stuckrath I, Heynck S, Beroukhim R, Lin W, Winckler W, Shah K, LaFramboise T, Moriarty WF, Hanna M, Tolosi L, Rahnenfuhrer J, Verhaak R, Chiang D, Getz G, Hellmich M, Wolf J, Girard L, Peyton M, Weir BA, Chen TH, Greulich H, Barretina J, Shapiro GI, Garraway LA, Gazdar AF, Minna JD, Meyerson M, Wong KK, Thomas RK (2009) Predicting drug susceptibility of non-small cell lung cancers based on genetic lesions. J Clin Invest 119 (6):1727-1740

Stone HB, Bernhard EJ, Coleman CN, Deye J, Capala J, Mitchell JB, Brown JM (2016) Preclinical Data on Efficacy of 10 Drug-Radiation Combinations: Evaluations, Concerns, and Recommendations. Transl Oncol 9 (1):4656. doi:10.1016/j.tranon.2016.01.002

Vendetti FP, Karukonda P, Clump DA, Teo T, Lalonde R, Nugent K, Ballew M, Kiesel BF, Beumer JH, Sarkar SN, Conrads TP, O'Connor MJ, Ferris RL, Tran PT, Delgoffe GM, Bakkenist CJ (2018) ATR kinase inhibitor AZD6738 potentiates CD8+ T cell-dependent antitumor activity following radiation. J Clin Invest 128 (9):3926-3940. doi:10.1172/JCI96519

Wang M, Kern AM, Hulskotter M, Greninger P, Singh A, Pan Y, Chowdhury D, Krause M, Baumann M, Benes CH, Efstathiou JA, Settleman J, Willers H (2014) EGFR-Mediated Chromatin Condensation Protects KRASMutant Cancer Cells against lonizing Radiation. Cancer Res 74 (10):2825-2834

Wang Y, Li J, Booher RN, Kraker A, Lawrence T, Leopold WR, Sun Y (2001) Radiosensitization of p53 mutant cells by PD0166285, a novel G(2) checkpoint abrogator. Cancer Res 61 (22):8211-8217

Wang Y, Li N, Jiang W, Deng W, Ye R, Xu C, Qiao Y, Sharma A, Zhang M, Hung MC, Lin SH (2018) Mutant LKB1 Confers Enhanced Radiosensitization in Combination with Trametinib in KRAS-Mutant Non-Small Cell Lung Cancer. Clin Cancer Res 24 (22):5744-5756. doi:10.1158/1078-0432.CCR-18-1489 
Willers H, Hong TS (2015) Towards an integrated understanding of epidermal growth factor receptor biology for radiation therapy: integrins enter. J Natl Cancer Inst 107 (2):dju440

Willers H, Keane FK, Kamran SC (2019) Toward a New Framework for Clinical Radiation Biology. Hematol Oncol Clin North Am 33 (6):929-945. doi:10.1016/j.hoc.2019.07.001

Yard BD, Adams DJ, Chie EK, Tamayo P, Battaglia JS, Gopal P, Rogacki K, Pearson BE, Phillips J, Raymond DP, Pennell NA, Almeida F, Cheah JH, Clemons PA, Shamji A, Peacock CD, Schreiber SL, Hammerman PS, Abazeed ME (2016) A genetic basis for the variation in the vulnerability of cancer to DNA damage. Nat Commun 7:11428. doi:10.1038/ncomms11428

Zhang Q, Green MD, Lang X, Lazarus J, Parsels JD, Wei S, Parsels LA, Shi J, Ramnath N, Wahl DR, Pasca di Magliano M, Frankel TL, Kryczek I, Lei YL, Lawrence TS, Zou W, Morgan MA (2019) Inhibition of ATM Increases Interferon Signaling and Sensitizes Pancreatic Cancer to Immune Checkpoint Blockade Therapy. Cancer Res 79 (15):3940-3951. doi:10.1158/0008-5472.CAN-19-0761 


\section{Figure Legends}

Fig. 1.1. Comparison of precision medicine concepts in medical oncology vs radiation oncology aka precision radiation medicine. CSCs, cancer stem cells.

Fig. 1.2. How do the Hallmarks of Cancer impact tumor response to radiation treatment? Redrawn from (Willers et al. 2019).

Fig. 1.3. Proposed preclinical pipeline for identifying "winning" targeted chemoradiosensitizers. Inspired by (Coleman et al. 2016). 


\section{Endpoint} Intent

Selectivity

Mechanism

Target

Biomarkers
Response

Chronic disease

Drug effective in a few

Drug targets tumor dependence

- Single drug target

- Increasing use of drug combos
Tumor control (kill all CSCs)

\section{Cure}

Radiosensitizer ideally effective in most tumors (similar to radiation effect)

- Radiosensitizing mechanism of action may be different from drug alone effect

-Ideally not toxic by itself

- Radiation has multiple effects

- Sensitizer may need to hit $>1$ target or a central mechanism (DNA repair)

- Understudied

- To identify radioresistant tumors, or/and predict radiosensitization 


\section{Hallmarks of Cancer for Precision Radiation Medicine}

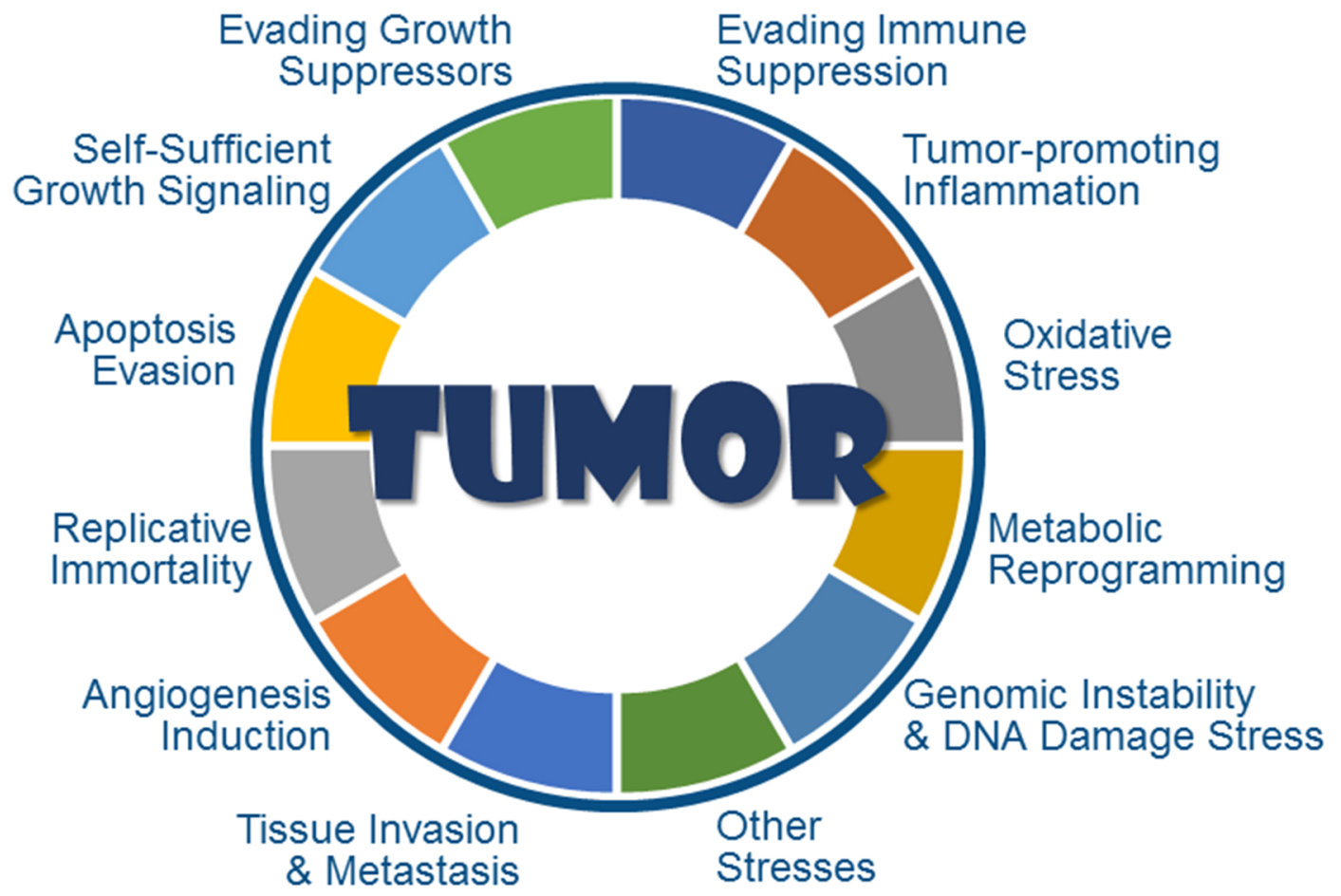

Impact on radiation responses in tumor vs normal tissues? 
